\title{
ECLETICA
}

www.scielo.br/eq

Volume 31, número 3, 2006

\section{A direct potentiometric titration study of the dissociation of humic acid with selectively blocked functional groups}

\author{
T. Andjelkovic ${ }^{\prime *}$, J. Perovic ${ }^{l}$, M. Purenovic ${ }^{l}$, S. Blagojevic ${ }^{2}$, R. Nikolic , \\ D. Andjelkovic ${ }^{3}$, A. Bojic $C^{l}$ \\ ${ }^{\prime}$ Faculty of Natural Sciences, University of Nis, Visegradska 33, 18000 Nis, Serbia \\ ${ }^{2}$ Faculty of Agriculture, University of Belgrade, Nemanjina 16, 11081 Belgrade, Serbia \\ ${ }^{3}$ Water Work Association "Naissus”, Kneginje Ljubice 1/1, 18000 Nis, Serbia \\ *Corresponding author: darkoa@bankerinter.net
}

\begin{abstract}
A direct potentiometric titration method was applied to commercial and soil humic acids in order to determine their carboxyl and phenol group concentrations and apparent and intrinsic pK. In that context, acid-base properties of humic acids are interpreted by selective blocking of carboxylic and phenolic groups by esterification and acetylation. Differences in underivatized and derivatized HA's acid-base properties are ascribed to carboxyl and phenol groups influence on total humic acidity. Potentiometric data were treated with the modified Henderson-Hasselbalch equation. Infra red results, the acidic group contents and the average values of apparent and intrinsic $\mathrm{pK}$ for underivatized and derivatized HAs confirmed the selectivity of esterification derivatization method. After blocking of the functional groups, the values of acidic group contents decreased, while the value of apparent $\mathrm{pK}$ increased after derivatization. Phenol groups cannot be specifically identified by the acetylation method, due to low selectivity of the acetylation method.
\end{abstract}

Keywords: humic acid; ionizable sites; derivatization; potentiometry.

\section{Introduction}

Humic substances (humic acids, HA and fulvic acids, FA) are heterogeneous macromolecular aggregates that form a main fraction of the natural organic carbon in soils, sediments and waters [1]. Owing to their widespread presence, humic substances (HS) play a significant role in the binding, transport and fate of different contaminants in soils and aquatic environments. The binding of contaminants to humic matter is related to their charge, thus the charging behavior of HA and FA describes complexation with heavy metal ions, nonpolar organic contaminant interactions and buffering characteristics [2]. The humic charge is controlled by the types and amounts of functional groups. Humic polyelectrolytic macromolecule possess the potential to carry predominantly negative charge, at naturaly occurring $\mathrm{pH}$ values, due to the dissociation of acidic functional groups, mainly carboxylic and phenolic [3]. Even though there are many papers dealing with the charge development $[2,4-6]$ there is still some uncertity about how humic functional group heterogeneity affects it [7]. Although the actual structural features of humic matter, including $\mathrm{HA}$, still remain unresolved, it is generally accepted that HA are heterogeneous polyelectrolyte possessing a variety of different types of functional groups which act as binding sites for proton/metal ions. The major 
binding sites are usually attributed to the oxygencontaining functional groups, although other less abundant functional groups, e.g. nitrogen and sulphur-containing groups, may also be important for cation binding [1,8]. Dominant oxygencontaining ionizable groups present in HA are carboxylic and phenolic groups, thus, the determination of theirs concentration and $\mathrm{pKa}$ 's can provide a guide to modeling HA acidity. Even though the concentrations of carboxyl and phenolic groups are among the most measured properties of HA and FA, it is still impossible to quantify unambiguously the separate contributions of each group type to the total acidity [9].

Determination of the nature of oxygen functionality is usually performed by direct and indirect potentiometric titrations [3], radiometric determination [10], infrared spectroscopy [11], carbon-13 nuclear magnetic resonance spectroscopy ( $\left.{ }^{13} \mathrm{C}-\mathrm{NMR}\right)$ [12] or ${ }^{29} \mathrm{Si}-\mathrm{NMR}$ [13]. Different derivatization techniques are usually applied in order to enhance and separate the NMR signals of the hydroxyl groups from the broad featureless spectra of HS [14-18]. However, in the present study we have combined derivatization techniques with potentiometry. Combination of those two approaches provided HA with selectively blocked functional groups, which could be used in comparison to untreated HA for estimation of the relative abundance of blocked functional groups.

Potentiometric acidity determination is performed by indirect or direct titrations. Direct titrations have disadvantage of the lack of distinct inflection points in the titration curves and the overlap of $\mathrm{pKa}$ values of acidic groups, and because of that indirect titration is still in use, even though it itself shows some limitations, as well [9,19-21]. Indirect titration, proposed by Schnitzer and Gupta [22], include titration of a filtered reaction mixture to a fixed $\mathrm{pH}$ end point, after a 24 hours equilibration with either $\mathrm{Ba}(\mathrm{OH})_{2}$ for determination of total acidity (TA) or with $\mathrm{Ca}(\mathrm{OAc})_{2}$ for determination of carboxylic acidity (CA). However, disadvantages of direct titrations can be exceeded by performing direct titration on derivative with selectively blocked carboxyl and/or phenolic functional groups. Therefore, the aim of this work was estimation of the relative abundance of carboxyl, phenol and alcohol groups in HA by their derivatization and acid-base potentiometric titration of the obtained derivatives. The selective blocking of carboxyl groups was achieved by esterification, while phenolic and alcoholic hydroxyls were blocked by acetylation. Acid-base properties of HA, the amount of total acid titrable groups $\left(\mathrm{C}_{\mathrm{Ac}}\right)$ and the average values of apparent and intrinsic $\mathrm{pK}$, were evaluated by potentiometric titration with the modified Henderson-Hasselbalch interpretation [23].

\section{Experimental}

\section{Humic acid preparation}

The soil HA isolation and purification is based on the method proposed by the International Humic Substances Society [24]. The soil sample was obtained from a well-humified organic horizon of old beech-forest soil (10 cm depth) in autumn 2003, air-dried and sieved to pass a 2.0 $\mathrm{mm}$ sieve. Briefly, HA was extracted from the soil with $0.1 \mathrm{M} \mathrm{NaOH}$ under $\mathrm{N}_{2}$ for 4 hours, under mixing conditions. The suspension was centrifuged (4500 rpm for $30 \mathrm{~min}$ ), the supernatant was acidified with $6 \mathrm{M} \mathrm{HCl}$ to $\mathrm{pH} 1.0$ and suspension was allowed to stand overnight. Precipitated HA was separated from FA by centrifugation $(4500 \mathrm{rpm}$ for $30 \mathrm{~min}$ ). Obtained HA precipitate was redissolved in $0.1 \mathrm{M} \mathrm{KOH}$, under $\mathrm{N}_{2}$. Solid $\mathrm{KCl}$ was added to attain $0.3 \mathrm{M}\left(\mathrm{K}^{+}\right)$and then suspension was centrifuged to remove suspended solids. The HA was reprecipitated with $6 \mathrm{M} \mathrm{HCl}$ to $\mathrm{pH}$ 1.0. The HA precipitate was suspended in a solution of $0.1 \mathrm{M}$ $\mathrm{HCl} / 0.3 \mathrm{M} \mathrm{HF}$. In order to minimize the ash content, this procedure was repeated three times. Obtained HA fraction was dialyzed in a Spectra/Por 7 membrane (molar mass cut-off = 1000 D), until no significant change in conductivity of dialysis bag external water was observed. Bound metal ions were removed by passing the HA solution through a Dowex 50W-X8 ( $\mathrm{H}^{+}$-form) column. The purified HA suspension was diluted in a volumetric flask and stored at $4^{\circ} \mathrm{C}$. HA from Aldrich (catalog H1,675-2 lot No S15539-264) was purified by the same procedure as soil HA in order to remove ash content, residual FA and heavy metals. The concentration of the stock sus- 
pensions of soil HA and Aldrich HA were determined as $2.51 \mathrm{~g} \mathrm{l}^{-1}$ and $2.47 \mathrm{~g} \mathrm{l}^{-1}$, respectively, by the dry weight of measured volume of well homogenized HA suspensions. Elemental composition $(\mathrm{C}, \mathrm{H}$ and $\mathrm{N})$ of soil $\mathrm{HA}$ and purified Aldrich HA were determined directly with Vario El 3, while oxygen was obtained by the difference.

\section{Derivatization of HAs}

Chemical modifications specific to carboxyl and phenol groups were achieved by esterification and acetylation, respectively. Carboxylic groups in soil and Aldrich HA were esterified and the obtained esterified derivatives (EHA) with methyl esters of carboxyl groups and unaffected phenolic and alcoholic groups were obtained (Fig. 1). Among many esterification methods described in the literature [25], probably one of the most attractive and efficient is the methanol-thionyl chloride procedure [25-28], which was modified and is thus described later in details. The applied methanol-thionyl procedure is an efficient route for the synthesis of methyl esters of substituted aromatic carboxylic acids without any affection of phenolic and alcoholic hydroxyl groups [28]. Due to its high selectivity, the method was suitable for functionally very heterogeneous humic macromolecule. Phenolic and alcoholic $\mathrm{OH}$ groups in soil and Aldrich HA were acetylated and acetylated derivatives (AHA) were obtained (Fig. 1). Acetylation of humic substances by refluxing with acetic anhydride and sulphuric acid is a commonly accepted method for determining the total hydroxyl content [29].

Esterification was performed by the following procedure: thionyl chloride $(5 \mathrm{ml})$ was added drop wise from a dropping funnel, to a stirred solution of $500 \mathrm{mg}$ of HA in $20 \mathrm{ml}$ of methanol, under ice-cooling (approximately - $5^{\circ} \mathrm{C}$ ), during 2 hours. The reaction mixture was then heated on a water bath for 5 minutes to decompose excess thionyl chloride. The suspension was than centrifuged at $2000 \mathrm{rpm}$ and the separated ester was washed with distilled water until it was free of chlorides. The ester was dried in a rotary evaporator and finally in a vacuum desiccator over $\mathrm{P}_{2} \mathrm{O}_{5}$. The esterification procedure was repeated and the obtained twice esterified product is marked as EHA. The obtained ester in the second esterification procedure was not dried, but was diluted and the concentration of the stock EHA suspension was determined as $1.25 \mathrm{~g} \mathrm{l}^{-1}$ and $1.45 \mathrm{~g} \mathrm{l}^{-1}$, for soil and Aldrich HAs, respectively.

Acetylation was also performed by adding of $15 \mathrm{ml}$ of acetic anhydride and 3 drops of conc. $\mathrm{H}_{2} \mathrm{SO}_{4}$ to $600 \mathrm{mg}$ of dried HA in 100-ml round-bottomed flask. Liebig reflux condenser was attached and the mixture was heated on a boiling water bath for 4 hours. The content was poured into $150 \mathrm{ml}$ of ice-water and vigorously stirred to assist the hydrolysis of unreacted acetic anhydride. The crystalline solid was filtered off and washed thoroughly with cold, distilled water until it was free of acid and then dried over $\mathrm{P}_{2} \mathrm{O}_{5}$ in a vacuum desiccator. The dry yield is $75 \%$ of the starting material. The acetylation procedure was repeated on the dry product obtained from the first acetylation. Twice acetylated product is marked as AHA. The obtained product from the second acetylation procedure, was not dried but was diluted in a volumetric flask and stored at $4{ }^{\circ} \mathrm{C}$. The concentration of the stock was determined as $1.05 \mathrm{~g}$ $\mathrm{l}^{-1}$ and $1.32 \mathrm{~g} \mathrm{l}^{-1}$ for soil and Aldrich HAs respectively, by dry weight of a measured volume of the homogenized suspension.

\section{Spectroscopic measurements}

FT-IR spectra of soil and Aldrich HA and their derivatives were recorded on $\mathrm{KBr}$ pellets (1.0

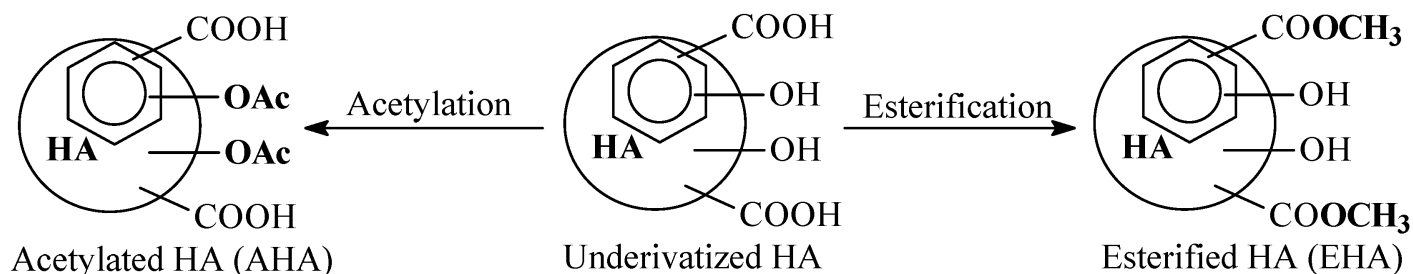

Figure 1. Reaction scheme for the synthesis of derivatized humic acids. 
mg HAs and $150.0 \mathrm{mg} \mathrm{KBr}$ ) using a Bomem Hartman \& Braun MB-Series FT-IR spectrophotometer.

\section{Potentiometric titrations and data treatment}

TA and CA were determined by indirect potentiometric titration method according to Schnitzer and Gupta [22]. Phenolic acidity (PA) was determined by the difference between TA and CA.

Suspensions of soil and Aldrich HA, and their derivatives were prepared in $0.1 \mathrm{M} \mathrm{NaCl}$ by diluting an appropriate volume of the stock suspensions with $25.00 \mathrm{ml} 0.2 \mathrm{M} \mathrm{NaCl}$ into a $50 \mathrm{ml}$ volumetric flask and diluted up to $50 \mathrm{ml}$ with decarbonated water. The whole volume was transferred in a titration vessel. The resulting suspensions concentrations were $500 \mathrm{mg} \mathrm{l}^{-1}$. Potentiometric measurements were made with Hach sension $3 \mathrm{pH}$-meter (precision of $0.1 \mathrm{mV}$ or 0.001 units of $\mathrm{pH}$ ) using Hach gel-filled combination glass electrode (51935-00). Throughout the titrations a $\mathrm{N}_{2}$ atmosphere was obtained over the solution, which was thermostated in a water bath at $25.0 \pm 0.1^{\circ} \mathrm{C}$. After introduction of electrodes, burette tip and the $\mathrm{N}_{2}$ conducting tube, the titration vessel was closed and maintained at a slight over pressure of nitrogen in order to exclude atmospheric $\mathrm{CO}_{2}$. Titrations were performed from $\mathrm{pH} 3$ to 11 with standardized, $\mathrm{CO}_{2}$-free solution of $\mathrm{NaOH}\left(0.0970\right.$ mol l-1 $\left.^{-1}\right)$ with the same $\mathrm{NaCl}$ concentration as the titrated HAs suspensions. The potential was read only when its variation was smaller than $0.555 \mathrm{mV} \mathrm{min}{ }^{-1}$, which is monitored by the drift control of the $\mathrm{pH}$ meter. Titrations were performed in triplicate.

The acid-base properties of HA, the total acid titrable group content $\left(\mathrm{C}_{\mathrm{Ac}}\right)$ and the average values of apparent $\mathrm{pK}\left(\mathrm{pK}_{\mathrm{app}}\right)$, were evaluated by potentiometric titration with the modified Henderson-Hasselbalch interpretation. The modified Henderson-Hasselbalch equation is usually used for analyzing potentiometric titration curves for weak polyacids:

$\mathrm{pK}_{\mathrm{app}}=\mathrm{pH}+\log ((1-\alpha) / \alpha)$

where $\mathrm{pK}_{\mathrm{app}}$ and $\alpha$ are the negative logarithm of the apparent acid dissociation constant and the degree of neutralization, respectively. The degree of neutralization, $\alpha$, of the HA at each point of alkali addition is defined by the equation:

$\alpha=\left([\right.$ base $\left.]+\left[\mathrm{H}^{+}\right]-\left[\mathrm{OH}^{-}\right]\right) / \mathrm{C}_{\mathrm{Ac}}$

where $[$ base $],\left[\mathrm{H}^{+}\right]$and $\left[\mathrm{OH}^{-}\right]$are the molarities of added base, free hydrogen ion and hydroxide ion, respectively, and $\mathrm{C}_{\mathrm{Ac}}$ is the total concentration of acid titrable groups, in mmol $\mathrm{g}^{-1}$, determined by a modified Gran relationship [30]. The $\left[\mathrm{H}^{+}\right]$and $\left[\mathrm{OH}^{-}\right.$ ] ions were obtained from the $\mathrm{pH}$ values assuming that activity coefficient is unity. Therefore, $\alpha=1$ at complete neutralization. Plots of $\mathrm{pK}_{\text {app }}$ versus $\alpha$ for a monomeric acid yield a unique line with a slope of zero. However, if the molecule exists as a polymeric assembly, such as humic macromolecule, a plot of $\mathrm{pK}_{\text {app }}$ versus $\alpha$ can give a quantitative measure of nonideality behavior by measuring any deviation from a straight line of zero slope [23]. The intrinsic dissociation constant $\left(\mathrm{pK}_{\mathrm{int}}\right)$ can be obtained by extrapolating the $\mathrm{pK}_{\text {app }}$ versus $\alpha$ curve to $\alpha=0$ and reading off the $\mathrm{pK}_{\mathrm{app}}$ value to be the negative logarithm of the intrinsic dissociation constant, while the average $\mathrm{pK}_{\mathrm{app}}$ value corresponds to the $\mathrm{pK}_{\text {app }}$ value at $\alpha=0.5$.

\section{Results and discussion}

The elemental compositions of soil HA and the obtained esterified (EHA) and acylated (AHA) preparations from soil HA, are summarized in Table 1. The molar elemental ratios were calculated from these values. All the obtained data for HA were consistent with typical values for soil humic acids [31]. The carbon content of EHA and AHA was increased by esterification and acetylation, while hydrogen and nitrogen contents remained almost the same. The increase of carbon content of EHA and AHA indicates the formation of methyl esters and ethers. The significant change in the sulphur content occurred in the acetylated preparation, due to addition of $\mathrm{H}_{2} \mathrm{SO}_{4}$ as catalyst during derivatization.

The FTIR spectra of unmodified Aldrich and soil HA samples exhibit the typical major peaks for humic acid: $3400 \mathrm{~cm}^{-1}$ absorption due to $\mathrm{H}$-bonded $\mathrm{OH}$ stetching of carboxyl, phenol and alcohol; 2920 and $2860 \mathrm{~cm}^{-1}$ band for aliphatic $\mathrm{CH}$ 
stretching; $1720 \mathrm{~cm}^{-1}$ for $\mathrm{C}=\mathrm{O}$ stretching from $\mathrm{COOH}$; $1600-1650 \mathrm{~cm}^{-1}$ for $\mathrm{C}=\mathrm{O}$ stretching of $\mathrm{COO}_{ \pm}$, ketonic $\mathrm{C}=\mathrm{O}$ and aromatic $\mathrm{C}=\mathrm{C}$ conjugated with $\mathrm{COO}_{ \pm} ; 1400 \mathrm{~cm}^{-1}$ for aliphatic $\mathrm{CH}$ bending and $\mathrm{COO}_{ \pm}$assymetric stretching [11]. The FTIR spectra of derivatized Aldrich HA samples (AHA and EHA) confirmed that esterification of the carboxyl groups and acetylation of hydroxyl groups occurred, due to the differences in the IR absorption before and after derivatization. There are three important IR regions related to these derivatization studies: (1) $3400 \mathrm{~cm}^{-1}$ absorption decrease in the spectra of modified HA samples comparing to a broad and strong peak of unmodified HA indicate that practically all hydroxyl groups have been derivatized. Reduction in $\mathrm{O} \alpha \mathrm{H}$ stretching vibrations intensity is more significant in EHA then in AHA spectra, confirming effective esterification, while acetylation was achieved only partially. Probably tertiary hydroxyls, which are acetylated under stronger conditions, were not acetylated [32]. (2) $1720 \mathrm{~cm}^{-1}$ absorption due to stretching vibration of $-\mathrm{C}=\mathrm{O}$ ester groups was increased by esterification and acetylation and (3) 1100 - $1450 \mathrm{~cm}^{-1}$ absorption due to $\mathrm{C}-\mathrm{O}$ stretching vibrations was increased, as well. Higher $\mathrm{OCH}_{3}$ content of EHA derivative is also indicated by the stronger bands for $\mathrm{C} \alpha \mathrm{H}$ stretching at 2920 and $2840 \mathrm{~cm}^{-1}$, than in HA. All evidenced

Table 1. Elemental analysis* and molar elemental ratios of original and modified soil HA samples.

\begin{tabular}{lccc}
\hline & \multicolumn{3}{c}{ Soil humic acid (modification) } \\
\cline { 2 - 4 } & HA (original) & AHA (acetylated) & EHA (esterified) \\
\hline $\mathbf{C ~ ( \% ) ~}$ & 55.74 & 60.02 & 58.63 \\
$\mathbf{H ~ ( \% )}$ & 5.45 & 5.23 & 5.47 \\
$\mathbf{N}(\%)$ & 0.86 & 0.62 & 0.72 \\
$\mathbf{O ~ ( \% ) ~}$ & 36.55 & 32.93 & 34.65 \\
$\mathbf{S ~ ( \% ) ~}$ & 1.40 & 2.85 & 1.57 \\
$\mathbf{H} / \mathbf{C}$ & 0.10 & 0.09 & 0.09 \\
$\mathbf{O} / \mathbf{C}$ & 0.66 & 0.55 & 0.59 \\
\hline
\end{tabular}

*All data are on ash- and moisture-free basis. changes in the IR spectra of Aldrich HA are consistent with the changes of soil HA IR spectra.

TA, CA and PA for underivatized and derivatized Aldrich and soil HAs are obtained by classical indirect titration methods, while the average values of $\mathrm{C}_{\mathrm{Ac}}$ are obtained by direct titrations. Esterification and acetylation decreased $\mathrm{C}_{\mathrm{Ac}}$ value, transforming ionizable groups to methyl esters and methyl ethers, respectively. Obtained $\mathrm{C}_{\mathrm{Ac}}$ values for $\mathrm{HA}$, EHA and AHA, could provide estimation of carboxyl and phenol groups contents of humic acid. Thus, after blocking of carboxyl groups in EHA derivative, the $\mathrm{C}_{\mathrm{Ac}}$ value for $\mathrm{EHA}, \mathrm{C}_{\mathrm{Ac}}(\mathrm{EHA})$, could be assigned to phenolic groups content of $\mathrm{HA},[\mathrm{Ph}-\mathrm{OH}]_{\mathrm{HA}}$, while difference between $\mathrm{C}_{\mathrm{Ac}}(\mathrm{HA})$ and $\mathrm{C}_{\mathrm{Ac}}(\mathrm{EHA})$, could be assigned to carboxyl group content of HA, $[\mathrm{COOH}]_{\mathrm{HA}}$ (Eq. (3) and (4), respectively):

$[\mathrm{Ph}-\mathrm{OH}]_{\mathrm{HA}}=\mathrm{C}_{\mathrm{Ac}}(\mathrm{EHA})$

$[\mathrm{COOH}]_{\mathrm{HA}}=\mathrm{C}_{\mathrm{Ac}}(\mathrm{HA})-\mathrm{C}_{\mathrm{Ac}}(\mathrm{EHA})$

Similary, after blocking of phenol groups in AHA derivative, the $\mathrm{C}_{\mathrm{Ac}}$ (AHA) value could be assigned to $[\mathrm{COOH}]_{\mathrm{HA}}$, while difference between $\mathrm{C}_{\mathrm{Ac}}(\mathrm{HA})$ and $\mathrm{C}_{\mathrm{Ac}}(\mathrm{AHA})$, could be assigned to $[\mathrm{Ph}-\mathrm{OH}]_{\mathrm{HA}}$ (Eq. (5) and (6), respectively):

$[\mathrm{COOH}]_{\mathrm{HA}}=\mathrm{C}_{\mathrm{Ac}}(\mathrm{AHA})$

$[\mathrm{Ph}-\mathrm{OH}]_{\mathrm{HA}}=\mathrm{C}_{\mathrm{Ac}}(\mathrm{HA})-\mathrm{C}_{\mathrm{Ac}}(\mathrm{AHA})$

The obtained results for Aldrich and soil HA and theirs derivatives are shown in Table 2. Estimation of $[\mathrm{Ph}-\mathrm{OH}]_{\mathrm{HA}}$ in Aldrich humic acid by Eq. (3), was $2.50 \mathrm{mmol} \mathrm{g}^{-1}$, which is in good correlation with results obtained by indirect titration methods: $\mathrm{PA}(\mathrm{HA})=2.54 \mathrm{mmol} \mathrm{g}^{-1}$ and $\mathrm{PA}(\mathrm{EHA})$ $=2.49 \mathrm{mmol} \mathrm{g}^{-1}$ (Table 2). Estimation of $[\mathrm{COOH}]_{\mathrm{HA}}$, by Eq. (4), was $3.82 \mathrm{mmol} \mathrm{g}^{-1}$, which is similar to the value obtained by indirect titration of HA: $\mathrm{CA}(\mathrm{HA})=3.94 \mathrm{mmol} \mathrm{g}^{-1}$ (Table 2). The results of indirect titrations of EHA derivative of Aldrich HA, show that carboxyl groups are almost complitely esterified, since only $7.9 \%$ of carboxyl groups were determined in EHA derivative $\left(\mathrm{CA}(\mathrm{EHA})=0.31 \mathrm{mmol} \mathrm{g}^{-1}\right)$, while $92.1 \%$ of carboxyls were blocked in the form of methyl esters. Likewise, phenolic groups content in EHA derivative was decreased for only $2.0 \%$, confirming high selectivity of the esterification method. 
Observed trend in acidity change has been checked on the isolated soil HA. Carboxyl group content in original HA is $2.80 \mathrm{mmol} \mathrm{g}^{-1}$, while phenolic group content is $1.88 \mathrm{mmol} \mathrm{g}^{-1}$ (Table 2). The obtained $\mathrm{C}_{\mathrm{Ac}}(\mathrm{EHA})$ value assigned to $[\mathrm{Ph}-\mathrm{OH}]_{\mathrm{HA}}$, in the case of soil $\mathrm{HA}$ is $1.76 \mathrm{mmol} \mathrm{g}^{-1}$, which is in good correlation with determination by indirect titration method of HA (1.88 mmol g ${ }^{-1}$ ) and EHA (1.76 $\left.\mathrm{mmol} \mathrm{g}^{-1}\right)$. Also, $\mathrm{C}_{\mathrm{Ac}}(\mathrm{HA})-\mathrm{C}_{\mathrm{Ac}}(\mathrm{EHA})$ value, assigned to $[\mathrm{COOH}]_{\mathrm{HA}}$ is $2.87 \mathrm{mmol} \mathrm{g}^{-1}$, which is similar to the value of $2.80 \mathrm{mmol} \mathrm{g}^{-1}$ obtained by indirect titration of HA. In the case of soil humic acid, carboxyl groups are also, almost complitely esterified $(92.9 \%)$, since only $7.1 \%$ of carboxyl groups $\left(\mathrm{CA}(\mathrm{EHA})=0.20 \mathrm{mmol} \mathrm{g}^{-1}\right)$ were determined in EHA derivative, while phenolic groups content in EHA derivative was decreased for $6.4 \%$.

These observations agree with IR data and lead to conclusion that the applied methanolthionyl procedure is selective, specific and efficient route for blocking carboxyl groups. Also, esterification followed by direct potentiometric titration can be used as method for carboxyl and phenol groups contents estimation.

After blocking of phenol groups in AHA derivative prepared from Aldrich humic acid, the $\mathrm{C}_{\mathrm{Ac}}(\mathrm{AHA})$ value, assigned to $[\mathrm{COOH}]_{\mathrm{HA}}$ was 2.05 mmol $\mathrm{g}^{-1}$ which is approximately twice reduced value compared to the value obtained by indirect titration of HA (Table 2). This is probably a consequence of low selectivity of the acetylation method. Acetic anhydride blocked carboxyl groups as well, which is confirmed by decrease in $\mathrm{COOH}$ content in AHA derivative for even $60.4 \%$ (only $1.12 \mathrm{mmol} \mathrm{g}^{-1}$ carboxyl groups were not in the ester form) (Table 2). Estimate of $[\mathrm{Ph}-\mathrm{OH}]_{\mathrm{HA}}$ on the base of $\mathrm{C}_{\mathrm{Ac}}(\mathrm{HA})-\mathrm{C}_{\mathrm{Ac}}(\mathrm{AHA})$ value is 4.27 mmol g-1, which is surprisingly high comparing to the PA(HA) value of $2.54 \mathrm{mmol} \mathrm{g}^{-1}$, obtained by the indirect titration of underivatized HA. The reason for this is probably the fact that phenolic groups cannot be completely blocked by acetylation, as $29.9 \%$ of phenolic $\mathrm{OH}$ groups were not blocked $\left(0.76 \mathrm{mmol} \mathrm{g}^{-1}\right)$ and were still determined after derivatization (Table 2). Similary, after blocking of phenol groups in AHA derivative prepared from soil humic acid, significant discrepancy between results obtained by direct titration after acetylation and indirect titration occurs (Table 2).

Summation of carboxyl and phenol groups contents determinations by indirect and direct titration method coupled with derivatization is shown in Table 3. A comparison of the obtained results shows that $[\mathrm{COOH}]_{\mathrm{HA}}$ and $[\mathrm{Ph}-\mathrm{OH}]_{\mathrm{HA}}$ estimations by indirect and direct titration method after esterification of HA are in agreement. However, differences between

Table 2. Total concentration of ionizable groups $\left(\mathrm{C}_{\mathrm{Ac}}\right)$ and total (TA), carboxyl (CA) and phenol acidities (PA) of underivatized and derivatized Aldrich and soil humic acids.

\begin{tabular}{|c|c|c|c|c|}
\hline & $\underset{\left(\mathrm{mmol} \mathrm{g}^{-1}\right)^{\mathrm{a}}}{\mathrm{C}_{\mathrm{Ac}}}$ & $\underset{\left(\mathrm{mmol} \mathrm{g}^{-1}\right)^{\mathbf{b}}}{\text { PA }}$ & $\underset{\left(\mathrm{mmol} \mathrm{g}^{-1}\right)^{\mathrm{b}}}{\mathrm{CA}}$ & $\begin{array}{c}\text { TA } \\
\left(\mathrm{mmol} \mathrm{g}^{-1}\right)^{\mathbf{b}}\end{array}$ \\
\hline \multicolumn{5}{|c|}{ Aldrich humic acid } \\
\hline HA & $6.32 \pm 0.15$ & 2.54 & 3.94 & 6.48 \\
\hline EHA & $2.50 \pm 0.10$ & 2.49 & 0.31 & 2.80 \\
\hline AHA & $2.05 \pm 0.08$ & 0.76 & 1.56 & 2.32 \\
\hline \multicolumn{5}{|c|}{ Soil humic acid } \\
\hline HA & $4.63 \pm 0.25$ & 1.88 & 2.80 & 4.68 \\
\hline EHA & $1.76 \pm 0.03$ & 1.76 & 0.2 & 1.96 \\
\hline AHA & $1.42 \pm 0.06$ & 0.60 & 1.12 & 1.72 \\
\hline
\end{tabular}

${ }^{a}$ Obtained by direct titrations. Standard deviations for three replicates.

b Obtained by indirect titrations. 
indirect titration method and direct titration method after acetylation are significant, confirming that the acetylation method could not be used for acidity determinations, due to low selectivity.

The Henderson-Hasselbalch plots (pH vs. $\log ((1-\alpha) / \alpha))$ for soil HA and its derivatives, shown in Fig. 2, are not linear confirming that HA posseses different types of ionic groups. The $\mathrm{pK}_{\text {app }}$ value for a simple monoprotic acid, such as $\mathrm{CH}_{3} \mathrm{COOH}$, is constant and independent of $\alpha$, while for polyacids, such as HA, it depends on $\alpha$. As it is expected, all three acids exhibit different acidic strengths. The $\mathrm{pK}_{\mathrm{int}}$ and the average $\mathrm{pK}_{\mathrm{app}}$ are increased after derivatization. Their values are related to the different chemical structure of the acids. The original HA is the strongest acid $\left(\mathrm{pK}_{\mathrm{app}}=4.28 \pm 0.05\right.$ and $\mathrm{pK}_{\text {int }}=$ $3.8 \pm 0.11$ ), as it possesses free carboxylic, phenolic and alcoholic groups. AHA is a weaker acid than $\mathrm{HA}\left(\mathrm{pK}_{\mathrm{app}}=5.17 \pm 0.02\right.$ and $\mathrm{pK}_{\text {int }}=$ $4.9 \pm 0.05)$, due to blocking of phenolic and alcoholic groups, with only carboxylic groups available for proton interaction. EHA is the weakest acid $\left(\mathrm{pK}_{\mathrm{app}}=5.80 \pm 0.04\right.$ and $\mathrm{pK}_{\mathrm{int}}=5.2$ \pm 0.03 ), because more acidic carboxylic groups are blocked, while less acidic phenolic are available, in this case, for proton interaction.

The $\mathrm{pK}_{\mathrm{app}}$ values distribute in the range $3.8 \pm 5.8$ for HA, $4.9 \pm 6.1$ for AHA and $5.2 \pm$ 6.6 for EHA (Fig 3.). The change in $\mathrm{pK}_{\text {app }}$ over the range of a values is the largest for HA $\left(\Delta \mathrm{pK}_{\mathrm{app}}=2.0 \mathrm{pK}\right.$ units $)$ compared to EHA

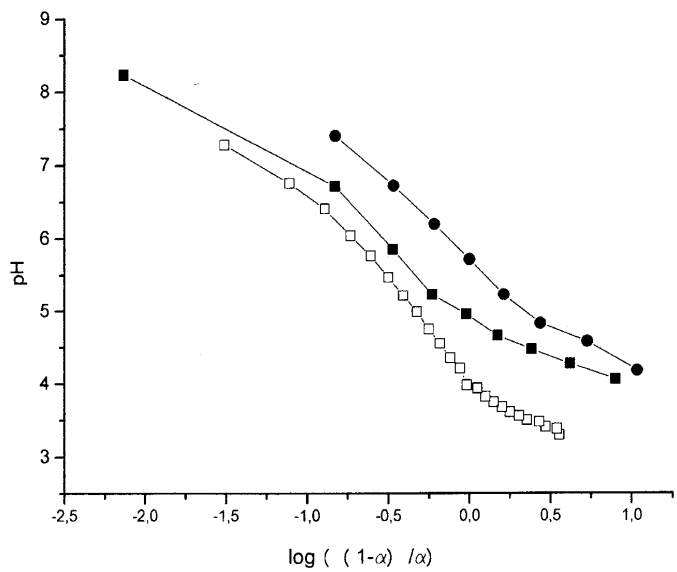

Figure 2. Henderson-Hasselbalch plot of soil HA $(\alpha)$, AHA $(\alpha)$ and $\operatorname{EHA}(\bullet)$.

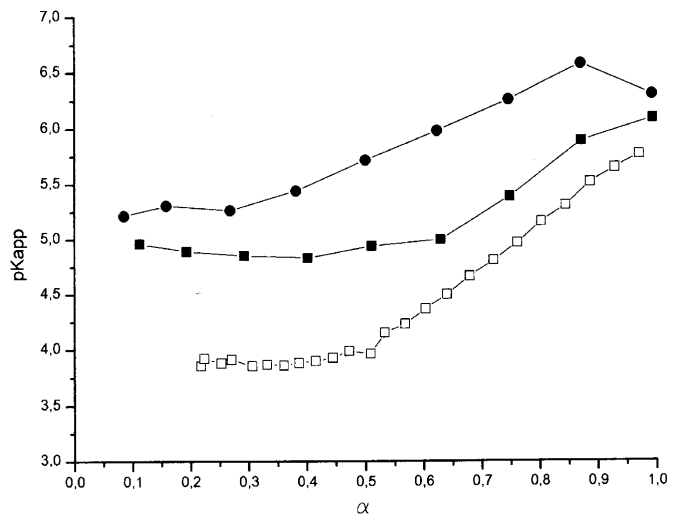

Figure 3. $\alpha$ vs.pK ${ }_{\text {app }}$ plot for soil HA $(\alpha)$, AHA $(\alpha)$ and $\operatorname{EHA}(\bullet)$.

Table 3. Carboxyl and phenol groups contents $\left(\mathrm{mmol} \mathrm{g}^{-1}\right)$ of Aldrich and soil humic acids obtained by indirect and direct titration methods.

\begin{tabular}{lccc}
\hline & $\begin{array}{c}\text { Indirect titration } \\
\text { method }\end{array}$ & $\begin{array}{c}\text { Direct titration/esterification } \\
\text { method }\end{array}$ & $\begin{array}{c}\text { Direct titration/ acetylation } \\
\text { method }\end{array}$ \\
\hline Aldrich humic acid & & & \\
Carboxyl group content & 3.94 & 3.82 & 2.05 \\
Phenol group content & 2.54 & 2.50 & 4.27 \\
Soil humic acid & & & \\
Carboxyl group content & 2.80 & 2.87 & 1.42 \\
Phenol group content & 1.88 & 1.76 & 3.21 \\
\hline
\end{tabular}


$\left(\Delta \mathrm{pK}_{\mathrm{app}}=1.4 \mathrm{pK}\right.$ units $)$ or AHA $\left(\Delta \mathrm{pK}_{\mathrm{app}}=1.2\right.$ $\mathrm{pK}$ units). The distribution of $\mathrm{pK}_{\mathrm{app}}$ values over the range of a values can give a quantitative measure of deviation from a straight line of zero slope which is characteristic for monomeric acid [23]. Thus, the highest $\mathrm{pK}_{\mathrm{app}}$ distribution was found in unmodified HA, polyprotic acid with the greatest number of free carboxylic, phenolic and alcoholic groups.

\section{Conclusions}

The approach outlined in this paper offers an opportunity to estimate the effect of carboxyl and phenol functional groups on total humic acidity, by comparing derivatized to underivatized HA acidbase properties, obtained by direct potentiometric data. Acid-base properties of HA, the acidic group content $\left(\mathrm{C}_{\mathrm{Ac}}\right)$ and the average values of apparent and intrinsic $\mathrm{pK}$ correlated well with IR spectra considerations of unmodified and modified HAs. Estimated carboxyl and phenol group content of isolated soil HA and Aldrich HA by direct titration after esterification is in agreement with results obtained by classical indirect titration methods. The applied methanol-thyonil esterification method obtained esterified derivative with over $92 \%$ of blocked carboxyl groups and only $2 \%$ of blocked phenolic groups. The values of $\mathrm{pK}_{\mathrm{int}}, \mathrm{pK}_{\mathrm{app}}$ and $\mathrm{pK}_{\mathrm{app}}$ distribution decrease by derivatization confirming the reduction in the number of free carboxylic, phenolic and alcoholic groups. The utilization of direct titration after esterification of HA method showed that the acidity data so obtained do represent the real content of the carboxyl and phenol groups.

Received 14 July 2006

Accepted 05 September 2006

\section{References}

[1] G.R. Aiken, D.M. McKnight, R.L. Wershaw, P. MacCarthy, eds., Humic substances in Soil, Sediment and Water, Wiley, New York, 1985, 13.

[2] M.J. Avena, L.K. Koopal, W.H. van Riemsdijk, J. Colloid Interface Sci. 217 (1999) 37.

[3] G.R. Aiken, D.M. McKnight, R.L. Wershaw, P. MacCarthy, eds., Humic substances in Soil, Sediment and Water, Wiley, New York, 1985, 493.
[4] J.A. Marinsky, J. Ephraim, Environ. Sci. Technol. 20 (1986) 349.

[5] F.J. Stevenson, Humus chemistry: Genesis, composition, reactions. John Wiley and Sons, New York, 1994.

[6] I. Christl, C.J. Milne, D.G. Kinniburgh, R. Kretzchmar, Environ. Sci. Technol. 35 (2001) 2515.

[7] I. Christl, R. Kretzchmar, Environ. Sci. Technol. 35 (2001) 2505.

[8] E. Tipping, Cation binding by humic substances. Cambridge University Press, Cambridge, 2002.

[9] E.M. Perdue, J.H. Reuter, M. Ghosal, Geochim. Cosmochim. Acta 44 (1980) 1841.

[10] S. Pompe, M. Bubner, M.A. Denecke, T. Reich, A. Brachmann, G. Geipel, R. Nicolai, K.H. Heise, H. Nitsche, Radiochim. Acta 74 (1996), 135.

[11] G.R. Aiken, D.M. McKnight, R.L. Wershaw, P. MacCarthy, eds., Humic substances in Soil, Sediment and Water, Wiley, New York, 1985, 527.

[12] G.R. Aiken, D.M. McKnight, R.L. Wershaw, P. MacCarthy, eds., Humic substances in Soil, Sediment and Water, Wiley, New York, 1985, 561.

[13] H. Herzog, P. Burba, J. Buddrus, Fresenius J. Anal. Chem. 354 (1996) 374.

[14] R.L. Wershaw, D.J. Pinckney, Science 199 (1978) 906.

[15] J.A. Leenheer, R.L. Wershaw, M.M. Reddy, Environ. Sci. Technol. 29 (1995) 393.

[16] J.A. Leenheer, R.L. Wershaw, M.M. Reddy, Environ. Sci. Technol. 29 (1995) 399.

[17] M.A. Mikita, C. Steelink, R.L. Wershaw, Anal. Chem. 53 (1981) 1715.

[18] S. Sachs, M. Bubner, K. Schmeide, G.R. Choppin, K.H. Heise, G. Bernharg, Talanta 57 (2002) 999.

[19] P. Dubach, N.C. Mahta, T. Jakab, F. Martin, Geochim. Cosmochim. Acta 28 (1964) 1567.

[20] H. van Dijk, The Use of isotopes in Soil Organic Matter studies, Pergamon Press, Oxford, 1986, 129.

[21] K.M. Holtzclaw, G. Sposito, Soil Sci. Soc. Am. J. 43 (1979) 318.

[22] M. Schnitzer, U.C. Gupta, Soil Sci. Soc. Proc. 27 (1965) 274.

[23] A. Katchalsky, P. Spitnik, J. Polymer Sci. 2 (1947) 432.

[24] D.L. Sparks, J.M. Bartels, J.M. Bigham eds., Methods of Soil Analysis. Part 3. Chemical Methods, Soil Science Society of America, Madison WI, USA, 1996, 1018.

[25] M.H.B. Hayes, P. MacCarthy, R.L. Malcolm and R.S.Swift eds., Humic substances II. In search of structure, John Wiley \& Sons, New York, 1989, 257.

[26] M. Schnitzer, S.I.M., Skinner, Soil Sci. 99 (1965) 278.

[27] A.I. Vogel, Vogel's textbook of practical organic chemistry, Longman Group Limited, 1978, London.

[28] B.D. Hosangadi, R.H. Dave, Tetrahedron Lett. 37 (1996) 6375.

[29] M. Schnitzer, in Proceedings of the International Meetings on humic substances, ed. D. Povoledo and H.L. Golterman, PUDOC, Wageningen, (1972), 293.

[30] D.S. Gamble, Can. J. Chem. 50 (1972) 2680.

[31] G.R. Aiken, D.M. McKnight, R.L. Wershaw, P. MacCarthy, eds., Humic substances in Soil, Sediment and Water, Wiley, New York, 1985, 457.

[32] M.H.B. Hayes, P. MacCarthy, R.L. Malcolm and R.S.Swift eds., Humic substances II. In search of structure, John Wiley \& Sons, New York, 1989, 409. 